\title{
Evaluation of pelvic asymmetry and lower limb functional shortening in a cohort of children re-examined after a ten-year observation
}

\author{
Anna Kluszczynska ${ }^{1 *}$, Adam Kluszczynski ${ }^{1}$, Jan Raczkowski ${ }^{2}$, Piotr Siwik ${ }^{3}$ \\ From 11th International Conference on Conservative Management of Spinal Deformities - SOSORT 2014 \\ Annual Meeting \\ Wiesbaden, Germany. 8-10 May 2014
}

\section{Background}

The study is a cohort study of children for the occurrence of pelvic asymmetry and functional lower limb shortening.

\section{Aim}

The aim of the study was to assess changes in the prevalence of symmetry of the pelvis and lower limb functional length in children and adolescents after a 10 year observation.

\section{Material and methods}

A group of 100 children and adolescents, aged 4-16 years, including 58 girls and 42 boys, were examined initially in 1997 and then re-examined 10 years later. Clinical examination was performed by the same observer (first author), using the same methodology. The exam consisted of: (1) clinical assessment of pelvic symmetry, (2) functional lower limb discrepancy assessment based on Rippstein plurimeter measurement of iliac spines position. Squared Chi test was used for comparison.

\section{Results}

The age at follow-up ranged from 14 to 26 years. Clinical pelvis asymmetry was identified in $23.8 \%$ and $71.4 \%$ of boys during the first and second exam, respectively and in $22.4 \%$ and $46.5 \%$ of girls, respectively. In boys, the functional lower limb discrepancy was found in $9.7 \%$ and $18.6 \%$ during the first and the second examination, respectively, with prevalence in respect to the left leg shortening $2.4 \%$ and the right leg $37.8 \%$, respectively, difference significant. In girls, in the first study, the functional shortening of the lower limb was found more frequently in the left leg $25.4 \%$ compared to $8.5 \%$ in the right. In the second study, the functional shortening of the left lower limb was found in $18.7 \%$ in $28.9 \%$ for the right one.

\section{Conclusions}

1. The second examination revealed a significant increase in occurrence of pelvic asymmetry.

2. After 10 years the functional shortening of one of the lower limbs increased in both sexes.

3. In the first study, a functional shortening of the left lower extremity predominated in the girls, while in the second study it was the right lower extremity and was identified in the boys.

\section{Authors' details}

${ }^{1}$ Troniny Children Rehabilitation Center, Częstochowa, Poland. ${ }^{2}$ Medical Sciences University, Lodz, Poland. ${ }^{3}$ Medical Sciences University of Varmia and Masuria, Olsztyn, Poland.

Published: 4 December 2014

doi:10.1186/1748-7161-9-S1-01

Cite this article as: Kluszczynska et al:: Evaluation of pelvic asymmetry and lower limb functional shortening in a cohort of children re-examined after a ten-year observation. Scoliosis 2014 9(Suppl 1):01.

${ }^{1}$ Troniny Children Rehabilitation Center, Częstochowa, Poland

Full list of author information is available at the end of the article 